COMUNIFE

Enero - Diciembre 2019, No.19: pp. 27-34

http://doi.org/ 10.33539/comunife.2019.n19.2438

Para utilizar este artículo debe incluir: Autor / Título / ISSN.

\section{DE LA NOTA DE PRENSA A LA NOTICIA UTILITARIA}

FROM THE PRESS RELEASE TO THE UTILITARIAN NEWS
Hellen Vásquez Chaparro

Directora de hv comunicación efectiva

Magister en Comunicaciones por la universidad San Martín de Porres docente universitaria

\title{
RESUMEN
}

En este artículo, se explica de qué manera el uso de una nota de prensa bien redactada permitirá la trasmisión de información relevante desde la empresa hacia los editores de noticias (en diversas plataformas informativas), así como su construcción para que se convierta en un material valioso y utilitario; y la forma cómo debe enviarse, para llamar la atención del periodista. Es importante recordar, que los periodistas pueden obtener la información presentándose en el lugar de los hechos (un evento, una rueda de prensa, etc.), o por una entrevista coordinada (con una entidad o personaje) o a través de una bien estructurada nota de prensa.

Palabras clave: Nota de prensa, periodistas, medios de comunicación, organizaciones, gabinete de prensa, relacionista público.

\section{ABSTRACT}

This article explains how the use of a well-written press release will allow the transmission of relevant information from the company to the news editors (on various information platforms), as well as its construction so that it becomes material valuable and utilitarian; and how it should be sent, to get the journalist's attention. It is important to remember that journalists can obtain the information by presenting themselves at the scene (an event, a press conference, etc.), or by a coordinated interview (with an entity or person) or through a well-structured note of press.

Keywords: Press release, journalists, media, organizations, press office, public relations officer. 


\section{INTRODUCCIÓN}

La comunicación externa es esencial para el buen desarrollo de los procesos comunicativos entre las empresas públicas y privadas y sus públicos de interés. En ese sentido, los medios de comunicación se identifican como un público de interés muy relevante, porque actúan como trasmisores de la información. Además de educar y entretener, los medios también informan y deben compartir noticias importantes para las audiencias. En ese sentido, los periodistas tienen la misión de obtener datos que completen sus espacios noticiosos, ya sea en televisión, radio, prensa escrita y prensa digital. Y para eso, necesitan recurrir a las fuentes informativas como las notas de prensa.

La nota de prensa es la herramienta más efectiva de comunicación entre un gabinete de prensa y los periodistas. Desde hace muchos años, los profesionales de la comunicación que se encargan de generar los vínculos entre las empresas y los medios de comunicación, han seguido fielmente la estructura de la nota de prensa tradicional. Debemos entender que, con la aparición de plataformas informativas digitales, los periodistas esperan recibir información valiosa, bien redactada, clara y precisa, que no necesite mucho cambio y que le permita generar contenidos interesantes para su medio; además de algunos complementos como videos, links, etc.

Las notas de prensa son herramientas de comunicación externa que utilizan los gabinetes de prensa, para relacionarse con los medios de comunicación. Son textos escritos en lenguaje sencillo, que permita la rápida comprensión del receptor y que atraiga su atención. Por lo general, se envían desde gabinetes de prensa, agencias de prensa y oficinas de comunicación.

Estas herramientas permiten el intercambio de información notable de las empresas u organizaciones, con periodistas locales $\mathrm{o}$ extranjeros. En ese sentido, los profesionales de la comunicación y relacionistas públicos esperan captar la atención de los periodistas con respecto a determinados temas, utilizando precisamente, la nota de prensa. El objetivo es lograr que la información que han compartido, se convierta en una noticia que ayude a impulsar la imagen de la empresa u organización. Es importante resaltar, que los medios de comunicación, son los canales a través de los cuales se proyectará esta imagen, ya sea en forma de artículo, reportaje, documental, informe especial, etc., a las audiencias. Por esta razón, los gabinetes de prensa se esfuerzan por generarcontenidos atractivos, interesantes, relevantes y utilitarios. Tan es así, que se desarrolla un vínculo muy estrecho entre el periodismo y las relaciones públicas: ambas disciplinas se complementan. Los periodistas saben que siempre podrán contar con el apoyo de los gabinetes de prensa, ya que una interesante información, puede provenir de una nota de prensa.

"Para mí, una nota de prensa es una forma de comunicación que tienen las instituciones para transmitir su mensaje a la prensa. Pienso que son muy útiles para expresar un mensaje e informar a los públicos objetivo de las novedades, logros y hechos de importancia de las empresas. Creo que han dejado de ser una carta impresa, y ahora son una forma de comunicación con enlaces y material adjunto en forma digital, donde la información se complementa con videos para ser más interesante. La nota de prensa es informativa y debe despertar la curiosidad del periodista", afirma Ernesto Pye, vicepresidente de la agencia de comunicaciones Pacific Edelman.

Pero, ¿cómo hacer para que esta herramienta consiga el tan ansiado impacto mediático? Se necesita práctica y conocimiento sobre la tipología de los medios de comunicación. Algunos gabinetes de prensa se han quedado en el tiempo, y siguen creyendo que las notas de prensa son suficientes para que el periodista se entere de lo que está pasando en las empresas. Esto está muy lejos de la realidad. La evolución es parte del aprendizaje, y hasta las notas de prensa tienen que evolucionar. Por su parte, la prensa también ha cambiado, no es la misma de años atrás. Los periodistas tienen una nueva metodología de trabajo y una nueva forma de generar de contenidos. Si tenemos clara esta transformación, no se cometerán errores. Por ejemplo, para el gabinete de prensa es inevitable que se produzcan noticias orgánicas (políticas, económicas, sociales, policiales, etc.) y que llenen más de la mitad de los diarios impresos, o que los 
programas de televisión le dediquen largas horas, eso no lo pueden controlar. Pero lo que sí pueden controlar, es la cantidad y calidad de impactos en los medios de comunicación, a partir de una nota de prensa bien elaborada y estratégicamente diferenciada. Y el reto es ese, lograr que la nota de prensa consiga un espacio dentro de la vorágine de información orgánica que se muestran día a día en los medios de comunicación y más aún, ¿cómo competimos con los videos generados por los llamados "periodistas ciudadanos" quienes, provistos de un Smartphone pueden registrar hechos que se viralizan, llegan a la televisión y ocupan varios minutos en un noticiero?

Diego Yrivarren, editor de un portal de noticias digital, comenta: "La nota de prensa es un artículo enviado a los medios para su posible difusión de acuerdo al rango de importancia que pueda tener para cada medio de comunicación. Podría ser valiosa siempre y cuando haya cierto rango de importancia. De hecho, si debe actualizarse diferenciando al medio digital con el formato tradicional. Generalmente nos envían notas informativas, muy pocas veces son utilitarias".

Con la aparición de nuevos medios de comunicación (hasta los medios tradicionales

ya tienen plataformas web y aplicaciones digitales), las notas de prensa tienen ser más

dinámicas, más atractivas. Atrás quedaron

las notas de prensa que solo contienen información densa, repetitiva, 'cherry' o que solo exponen las bondades de la organización.

$Y$, de acuerdo con mi experiencia, el periodista de hoy requiere de datos útiles que le sirvan a su audiencia, para que sus lectores,

oyentes o radioescuchas; puedan aprender algo de la información que consumen. No es solo mandar notas de prensa con la intención

que conseguir publicity. El gabinete de prensa debe saber que el ritmo de trabajo en

los medios de comunicación ha cambiado, porque el usuario se ha vuelto más exigente y consume contenidos con más velocidad que antes. Por ejemplo, el nuevo lector digital solo revisa lo que le interesa y si se aburre en un medio, inmediatamente elegirá otro. Es decir, ya no es fiel a un medio o a un periodista en particular, es fiel a la plataforma que le ofrezca mejores y más contenidos. $\mathrm{Y}$ eso se debe, a que el entorno virtual ofrece mayores posibilidades de exploración y conocimiento.
Los nuevos medios

Entendemos que el proceso de la comunicación es bidireccional y que el emisor siempre espera una respuesta del receptor. Para que el proceso funcione, debe existirla intención -por parte de ambos- de enviar, recibir y responder. En este caso, podríamos darle al gabinete de prensa el rol del emisor y a los medios de comunicación, el rol del receptor. Para que ambos lleguen a un buen entendimiento, debe existir comunicación efectiva. Y esta comunicación efectiva se va a producir, en la medida que ambosse conozcan a la perfección. Por ejemplo, y siguiendo la tipología de los medios, la televisión y la radio generan en los públicos, emociones. La prensa escrita les hace pensar y la prensa digital, incluyendo las redes sociales, les permiten a los públicos, ser más participativos.

\begin{tabular}{|c|c|c|c|}
\hline TELEVISIÓN & RADIO & $\begin{array}{l}\text { PRENSA } \\
\text { ESCRITA }\end{array}$ & $\begin{array}{c}\text { WEB/ } \\
\text { DIGITAL }\end{array}$ \\
\hline $\begin{array}{l}\text { La información } \\
\text { es entreteni- } \\
\text { miento. }\end{array}$ & $\begin{array}{l}\text { La } \\
\text { información } \\
\text { es } \\
\text { conocimien- } \\
\text { to. }\end{array}$ & $\begin{array}{l}\text { La } \\
\text { información } \\
\text { crea opi- } \\
\text { nión. }\end{array}$ & $\begin{array}{l}\text { La } \\
\text { información } \\
\text { crea } \\
\text { tendencias. }\end{array}$ \\
\hline $\begin{array}{l}\text { Tiene una } \\
\text { audiencia } \\
\text { masificada. }\end{array}$ & $\begin{array}{l}\text { Tiene } \\
\text { audiencia } \\
\text { fidelizada. }\end{array}$ & $\begin{array}{l}\text { Tiene } \\
\text { audiencia } \\
\text { masificada } \\
\text { y especiali- } \\
\text { zada. }\end{array}$ & $\begin{array}{l}\text { Tiene } \\
\text { audiencia } \\
\text { diversa. }\end{array}$ \\
\hline $\begin{array}{l}\text { Transmite la } \\
\text { información } \\
\text { en el momento } \\
\text { que sucede. }\end{array}$ & $\begin{array}{l}\text { Transmite } \\
\text { la informa- } \\
\text { ción inme- } \\
\text { diatamente } \\
\text { después } \\
\text { que sucede. }\end{array}$ & $\begin{array}{l}\text { La informa- } \\
\text { ción incluye } \\
\text { análisis (se } \\
\text { lee al día } \\
\text { siguiente). }\end{array}$ & $\begin{array}{l}\text { La informa- } \\
\text { ción tam- } \\
\text { bién sirve } \\
\text { para ofrecer } \\
\text { productos o } \\
\text { servicios. }\end{array}$ \\
\hline $\begin{array}{l}\text { El periodista } \\
\text { cuenta la } \\
\text { noticia desde } \\
\text { su perspectiva. }\end{array}$ & $\begin{array}{l}\text { El } \\
\text { periodista } \\
\text { tiene poco } \\
\text { tiempo para } \\
\text { trabajar la } \\
\text { informa- } \\
\text { ción. }\end{array}$ & $\begin{array}{l}\text { El } \\
\text { periodista } \\
\text { tiene más } \\
\text { tiempo para } \\
\text { analizar la } \\
\text { información } \\
\text { y contras- } \\
\text { tarla. }\end{array}$ & $\begin{array}{l}\text { Los } \\
\text { periodistas } \\
\text { tienen que } \\
\text { actualizar la } \\
\text { información } \\
\text { en tiempo } \\
\text { real. }\end{array}$ \\
\hline
\end{tabular}

Fuente: Elaboración propia

La nota de prensa si bien es valiosa, también se convierte en una peligrosa arma cuando se escriben de manera incorrecta, es decir, cuando los redactores no respetan la regla de la pirámide invertida (después de todo, la nota de prensa es como un artículo periodístico) o utilizan oraciones muy complejas y párrafos muy largos. Quienes 
3 la escriben, deben priorizar los hechos de acuerdo a su importancia y a los objetivos comunicacionales que tenga la empresa u organización, porque son los voceros (ejecutivos) quienes finalmente deciden qué decirles a los grupos de interés y qué no.

Es importante recordar que, si no se tiene nada que comunicar, mejor no se comunica. En las notas de prensa se debe aplicar este criterio. Es decir, el gabinete de prensa debe conocer al medio, sus características, el tratamiento que le dan a la noticia, cuáles son sus programas, secciones $\mathrm{o}$ espacios noticiosos, quienes son sus redactores, productores, jefes de información, directores, editores; es decir, debe conocer el medio al detalle. Sin esta data, la información que el gabinete envíe a través de la nota de prensa, podría terminar en la papelera de reciclaje. Los periodistas que han recibido una nota de prensa, primero interpretan la información, luego analizan si sus públicosla encontrarán interesante por ser novedosa, importante, de interés humano, etc., luego le dan una valoración, seleccionan los datos y finalmente, la publican o divulgan. Es por eso que se debe tener mucho conocimiento sobre lo que se quiere informar.

"A lo largo de mi carrera, he visto que algunos de los encargados de gestionar la prensa de una empresa u organización,no saben ni siquiera a quienes se dirigen (periodistas), y envían la misma nota de prensa en un correo masivo, sin distinguir si es radio, prensa o televisión. Entiendo que esta es una práctica común, pero no es muy efectiva. Los periodistas esperan un poco más de exclusividad, dado que sus contenidos varían de acuerdo a su línea editorial", (Editor de Noticias, comunicación personal).

Enviar la misma nota de prensa a todos los medios de comunicación por igual, es perder el enfoque de lo que se quiere lograr. $\mathrm{O}$ tal vez, enviar la misma nota de prensa al mismo tiempo y a los mismos medios permita obtener un mayor impacto mediático. Entonces,

¿Cómo lograr que la información se considere noticiable? Por lo general, el periodista que recibe la nota no responde, a menos de que se haya interesado por el tema. $Y$ eso, es un poco difícil de conseguir.

"A veces, cuando reviso mi bandeja, veo una nota de prensa que ha llegado en correo masivo y encuentro direcciones de correo con nombres de periodistas deportivos, cuando la información no tiene relación con mi sección de salud. También encuentro direcciones de Hotmail $u$ otros que no generan confianza. Y me pregunto si el gabinete de prensa hace algún tipo de filtro. Empezando por enviar un correo masivo. Me parece que no piensan en la calidad del impacto. Solo lo mandany esperan a que funcione la táctica. Cuando eso sucede, siento que me consideran unomás del montón de periodistas y no lo veo como algo correcto. Creo que deberían darlesa todos, la importancia que se merecen, independientemente si somos de un medio grande o uno chiquito", (Practicante Redactor Web, comunicación personal).

A todo esto, hay que sumarle el hecho de que los medios de comunicación ya no son tradicionales, son dinámicos y modernos. Ahora se deben a un público más diverso, más exigente. Por eso tienen que marcar la diferencia con los demás y captar la mayor cantidad de público. En ese sentido, los públicos también han cambiado y ya no son tan fieles como antes. Tan es así, que,si no encuentran la información en un medio, inmediatamente pasan a otro y así, sucesivamente. Los medios de comunicación han tenido que adaptarse al entorno digital, a los nuevos hábitos de consumo de información, y han ampliado su espectro informativo: ahora son, multiplataforma. En este sentido, los gabinetes de prensa deben darse cuenta que la información que le envían a RPP, por ejemplo, no puede serla misma que le envían al diario Karibeña, porque, además de ser formatos distintos, sus periodistas no tratan la información de la misma manera. Es importante pensar en lo que el periodista necesita para mantener a sus propios públicos interesados, con información variada y original.

“El diario Karibeña es utilitario, es decir, publicamos noticias que además de informar, les permiten a los lectores conocer, aprender, utilizar, etc. Siempre revisamos las notas de prensa porque son valiosas como fuentes de información y esperamos recibir contenido que no sea inexacto o publicidad encubierta", dice Felipe Gamonal, director del diario Karibeña, que pertenece al grupo Exitosa.

Cuando un gabinete de prensa envía una 
nota, espera como mínimo que el periodista lea la información que esta contiene. El objetivo de una nota de prensa es claro: conseguirque los periodistas utilicen la información y elaboren artículos, entrevistas o reportajes. Pero ¿qué pasa cuando el periodista descubre que este gabinete, envió la misma nota a varios medios de comunicación? Muchas notas de prensa son enviadas usando mailing. A veces, el que envía la nota no se percata siquiera, si el asunto del correo está bien escrito, si ha cambiado el nombre del periodista o si está en copia oculta.

"Considero que se ha normalizado la idea de que es mejor enviar notas a granel, por una cuestión de tiempo, pero no creo que sea efectivo. Los periodistas no queremos repetir lo mismo, cada uno tiene un público al cual entretener, informar y educar. Las notas de prensa que envían las organizaciones, nos sirven para generar contenido que no tiene nada que ver con lo cotidiano que son los hechos políticos, económicos o deportivos. Por eso es tan importante que el gabinete nos proporcione la información, pero de manera diferenciada a todos los medios, solo así, tendrá más oportunidades de ser publicado. Si veo que es más de lo mismo, no lo voy a considerar", explica el director de Karibeña.

Algunos periodistas, también me comentan la razón de esta falta de diversificación. "Creo que los asesores de prensa o relacionistas públicos envían la misma información a través de un correo masivo porque piensan que a más correos enviados, más posibilidades de ser publicados tendrán. Me parece que eso sucede con los portales de noticias web, más que con los medios tradicionales. Ellos tienen más facilidad de editar las notas. La verdad es que no todos los periodistas leemos cada una de las notas de prensa que nos envían. Pienso que sería mejor que los gabinetes envíen correos personalizados, así tendrían más oportunidades que el resto". (Periodista diario impreso, comunicación personal).

"Yo recibo notas de prensa a diario, a veces llegan con mi nombre, otras con nombres de otras personas. Pienso que es por el apuro, porque a los PR también les exigen resultados y eso se manifiesta en los impactos que puede tener su nota de prensa en diferentes medios. Aunque no justifico que se envíen por enviar, pienso que deberían tener un poco más de preparación porque lo que hacen es una contribución al periodismo, ya que sus notas aparecen en un medio de comunicación, son textos que ellos mismos han escrito. Aún hay muchos juniors que no comprender la importancia de su trabajo, por eso que no reparan en los detalles". (Editora de Noticias, comunicación personal).

\section{La importancia de la redacción}

Una nota de prensa debe ser elaborada con mucho cuidado y con un enfoque basado en el contenido. Independientemente si se envían a periodistas de prensa escrita, radial, televisiva o digital; constituyen una fuente de información y por eso, su contenidodebe ser redactado siguiendo la rigurosidad de las reglas gramaticales. Cada vez que se envía una nota de prensa, se expone la imagende una empresa u organización y los datos del emisor (incluye el nombre del asesor de prensa o relacionista público y el nombre de la agencia para la que trabajan). Es claro que la imagen que la empresa quiere proyectar debe ser positiva, pero si la nota de prensa está mal escrita ¿de quién es la responsabilidad? Es bien sabido que los textos deben pasar por la aprobación del cliente antes de ser enviada. ¿Entonces? En muchas ocasiones, quienes redactan las notas de prensa no revisan la estructura de los textos antes de enviarla, pudiendo causar daños en la imagen de los involucrados.

A decir de Hernández () el primer paso es un buen titular, vale decir, que atraiga la atención, que "invite" a leer la noticia. Las funciones del titular son:

- Anunciar y resumir la información tratada a continuación.

- Da vida a la página de publicación escrita.

- Ser la síntesis de la noticia.

- No aludir o introducir: Contar la información.

Dominar la gramática debería ser una competencia inherente a cada comunicador, pero a veces, el texto deja mucho que desear. "Es que no se toma en cuenta al periodista. Los PR (relacionista público) creen que vamos a leer todas sus notas de prensa. 
A nosotros nos llegan muchos correos al día de distintas empresas. A veces las seleccionamos solo por el asunto del correo y si nos parece interesante lo abrimos y si no, para otra oportunidad será. Y lo peor, es que cuando vemos que la nota de prensa que tiene potencial, nos encontramos con que tiene más de tres páginas, los contenidosno tienen un orden lógico, hay demasiados errores de sintaxis, y nosotros no tenemos tiempo de hacer la tarea de otros", afirma una colega de un medio de comunicación local. (Periodista medio local, comunicación personal).

Hay que considerar también que muchos periodistas, por una cuestión de tiempo, a veces solo "pegan" la nota de prensa en su canal de noticias digitales, con todo y faltas ortográficas. "Nosotros confiamos en que las notas de prensa han sido revisadas antes de que lleguen a la bandeja, y a veces cometemos el error de no revisar antes, porque en los canales digitales prima la inmediatez que a veces se confunde con primicia. Debemos hacer un Mea culpa en el sentido que debemos ser más rigurososcon la información que compartimos con los usuarios, ya que nuestra reputación como medio, también está en riesgo y no podemos publicar artículos con faltas ortográficas", afirma una colega del periodismo digital (Periodista digital, comunicación personal).

Por eso, es de suma importancia queel gabinete de prensa envíe una nota relevante y bien redactada porque, refleja el profesionalismo de la empresa $u$ organización y por supuesto, del relacionista público o asesor de comunicaciones. "Noes lo mismo generar contenidos para una página impresa o para un programa de radio.Los que escriben las notas de prensa deben redactar con mucho criterio y siguiendo las reglas básicas de redacción. No porque sean relacionistas públicos tienen licencia para cometer errores". (Docente de periodismo, comunicación personal).

"La nota de prensa contiene información emitida por una empresa u organización del Estado que busca difundir un hecho relevante de su interés, en los medios de comunicación masivos. Si están bien redactadas y tienen buen contenido, serán valiosas para el medio de comunicación y los jefes de prensa la incluirán en su pauta diaria. Además, tendrán a la empresa en su mente para futuras declaraciones, participaciones en entrevistas o servirán de fuente para un tema determinado etc.", dice Patricia Altamirano, docente universitaria.

Hay un aspecto importante también a considerar: el estilo periodístico. Cuandose escribe una nota de prensa, se debe pensar en el receptor. El periodista está acostumbrado a sintetizar, a levantar su contenido por 'la pepa', a buscarle el sentido a la noticia. Por eso, estos textos deben ser lo más atractivos, periodísticamente hablando. Las notas de prensa no son los brochures de la organización. Deberían ser herramientas que permitan la conexión entre lo que quiere decir la organización y la prensa, reforzando los mensajes claves. Estos mensajes claves le darán vida a la nota de prensa, la harán brillar y podrán encontrar un espacio en el periódico, en la revista, en el programa de radio o en el canal de noticias digital.

\section{La empresa u organización como fuente para las notas de prensa}

Las empresas $u$ organizaciones que trabajan con gabinetes de prensa, deberían saber que las notas de prensa que se redactar, tienen que convertirse en noticia. Por eso, los voceros (ejecutivos) le deben proporcionar al relacionista público o asesor de prensa, todos los datos necesarios para que pueda elaborar un material que sea digno de admiración y de seguimiento por parte de los periodistas de los diferentes medios de comunicación.

“En mi negocio nos enfocamos a producir, y al principio no le prestaba mucha atención a la comunicación. Cuando me dijeron que era necesario incluir en nuestra estrategia comercial a las relaciones públicas, lo dudé porque no estaba familiarizado con el tema, pero luego comprendí que debía dar aconocer nuestras acciones a los públicos, y entablar relaciones con la prensa. Tan es así, que contratamos a un gabinete de prensa que comenzó a trabajar comunicados y notas de prensa, pero no fue fácil, ya que el asesor no entendía el lenguaje técnico que usamos en la empresa. Creo que es necesario que el encargado de trasmitir nuestra 
información, no solo sepa comunicar, sino, sepa qué comunicar, porque al final nosotros teníamos que corregir todo el texto de su nota de prensa y eso me quitaba mucho tiempo", afirma Jorge Tuesta, gerente comercial de una empresa dedicada al rubro de las autopartes.

Es necesario que los gabinetes de prensa le expliquen a su cliente, que, como partede la estrategia de comunicación, se van a elaborar notas de prensa que constituirán el primer acercamiento con el periodista, y cuya función es impulsar la imagen de laempresa hacia todos sus públicos objetivos. En ese sentido, el gabinete debe recopilar toda la información necesaria utilizando diversas herramientas de recojo de datos tales como el Q\&A, encuestas, entrevistas a profundidad, Media Training, entre otras.

\section{Información versus Noticia}

La nota de prensa debe contener información importante y relevante, aunque estos atributos no siempre van juntos. A veces, los que escriben los textos no se dan cuenta del impacto que estas herramientas pueden tener: mientras más explicado sea el tema, mejor será para los periodistas, porque así ellos lo podrán explicar mejor a sus públicos. Pero antes de escribirlas, los gabinetes de prensa deben definir el público objetivo (es decir, a los medios de comunicación más adecuados para trasmitir la información) y lo más importante, se debe utilizar un lenguaje periodístico.

“Las agencias de prensa redactan lasnotas de prensa pensando en ellos, no en los periodistas. Nosotros no podemos adivinar qué es lo que quieren decir con su nota, y tenemos que releerla y eso evita que avancemos con otros temas. Hoy, las salas de redacción trabajan con el tiempo ajustado, especialmente cuando debemos subir los contenidos a la web, por eso cuando una nota de prensa está bien escrita, nos ayudaa generar más tráfico para nuestro medio y para su empresa; pero cuando es una nota de prensa que tiene hasta tres páginasy contenido incomprensible, pues, nos perjudica a todos", señala una editora de sociales de un medio local (comunicación personal).
Las notas de prensa deben actualizarse y acompañarse de videos, fotografías y demás materiales. Lo ideal, es no perder lo básico. En ese sentido, todo va a depender del medioal que te dirijas. Por ejemplo, si el gabinete de prensa quiere que la información aparezca en medios web, deben acompañar la información de recursos visuales. Si es para televisión, incluir videos. Para radio, deben enviar la nota con audios y para diarios o revistas impresas, con fotografías de alta calidad. Estos detalles harán que la nota de prensa no sea vista por los periodistas solo como un documento, sino como un material digno de ser revisado y analizado para su posible publicación o difusión.

“Ese es un problema que ahora se nota más que antes. Lo que se escribe para unmedio escrito debe ser muy diferente a loque se debería enviar para una plataforma digital, en vista que los canales digitales son más interactivos y se puede incluir gifs, flyers llamativos, gráficos y sin tanto texto. Creo que la información que contiene la notade prensa puede ser utilitaria e informativa, dependiendo del tema y de su construcción. En todo caso, se debe buscar que la nota sea lo más interesante y visual posible, además de utilitaria e informativa". (Docente universitaria, comunicación personal).

\section{CUADRO 2: DIFERENCIAS}

\begin{tabular}{|c|c|}
\hline N.P TRADICIONAL & N.P MODERNA \\
\hline Más de 3 páginas. & $\begin{array}{l}\text { Una página y media como } \\
\text { máximo. }\end{array}$ \\
\hline Información con "relleno". & Información puntual. \\
\hline $\begin{array}{l}\text { Ofrece solo datos } \\
\text { informativos. }\end{array}$ & $\begin{array}{l}\text { Contiene información que } \\
\text { combina lo informativo con } \\
\text { lo utilitario. }\end{array}$ \\
\hline $\begin{array}{c}\text { No se escribe pensando } \\
\text { en el SEO. }\end{array}$ & $\begin{array}{l}\text { Se escribe pensando en el } \\
\text { análisis SEO. }\end{array}$ \\
\hline $\begin{array}{c}\text { Títulos largos que no } \\
\text { impactan. }\end{array}$ & $\begin{array}{l}\text { Títulos con datos } \\
\text { impactantes. }\end{array}$ \\
\hline $\begin{array}{l}\text { No se ajustan al diseño } \\
\text { establecido (márgenes, } \\
\text { tipografía, uniformidad } \\
\text { en los párrafos, imágenes } \\
\text { incrustadas). }\end{array}$ & $\begin{array}{c}\text { Respeta la forma y se ajusta } \\
\text { al contenido. }\end{array}$ \\
\hline Se acompaña solo con fotos. & $\begin{array}{l}\text { Se acompaña con fotos, } \\
\text { videos, enlaces multimedia, } \\
\text { videocomunicados, RR.SS }\end{array}$ \\
\hline $\begin{array}{l}\text { Se comete el error de } \\
\text { enviarla en pdf. }\end{array}$ & $\begin{array}{l}\text { Se envía en formato } \\
\text { editable. }\end{array}$ \\
\hline
\end{tabular}

Fuente: Elaboración propia. 


\section{Conclusiones}

Finalmente, las notas de prensa son documentos que nunca pasarán de moda, a menos, que los gabinetes de prensa y comunicadores inventen nuevas formas de comunicarse con los periodistas. Pero esta posibilidad, es casi imposible. Si bien es cierto, las Relaciones Públicas se van adaptando a las necesidades tanto de los gabinetes de prensa, como de las empresas y organizaciones y de los mismos periodistas; las herramientas de comunicación también deben adaptarse a las nuevas plataformas y a los nuevos usuarios. Es necesario que los jóvenes comunicadores que decidan trabajar en gabinetes de prensa o tengan entre sus funciones enviar notasde prensa, comprendan que es necesario prestarles atención a los detalles, porque eso hará que se diferencien del resto. Escribir bien una nota de prensa, es sinónimo de excelencia, de compromiso con la empresa y con su profesión. No deben trabajar solo porque deben hacerlo, deben, además, adquirir experiencia para lograr que su nota de prensa, sea reconocida por la prensa y que su trabajo sea reconocido por sus clientes.

\section{REFERENCIAS BIBLIOGRÁFICAS}

Busto-Salinas. L. (2012) Aplicación dela teoría de la redacción periodística a la notade prensa. Revista de Comunicación Vivat Academia. España.

Hernández, F. (2015) Comunicación Corporativa. Solé y Hernández Consultores. España.

Wilcox, D. Cameron,G. Xifra, J.(2006) Relaciones Públicas. Estrategias y Tácticas. $8^{\underline{a}}$ ed. Pearson Educación, S. A. España. 